\title{
SUPRAMOLECULAR $p$-SULFONATED CALIX[4]ARENE FOR TYROSINE DETECTION
}

\author{
Xu-Yan ZHANG ${ }^{\mathrm{b}}$ and Tao-Tao PANG ${ }^{*}$,a \\ ${ }^{a}$ Analytical and Testing Center, Shanxi Normal University, Linfen, 041004, P. R. China \\ ${ }^{\mathrm{b}}$ State Key Laboratory of Coal and CBM Co-mining, Taiyuan University of Science and Technology, Taiyuan, 030024, P. R. China
}

Received April 17, 2018

\begin{abstract}
Numerous techniques have focused on the ability of $p$-sulfonated calix[4]arene to form complexes with tyrosine. Scanning electron microscopy and Fourier transform infrared spectroscopy and ultraviolet spectroscopy were utilized to study the organization and molecular structure of different layers of the electrode surface. A novel and ultrasensitive electrochemical sensor based on $p$-sulfonated calix[4]arene modified gold electrode for determination of tyrosine in some high tyrosine foods including cheese, eggs and yogurt was reported. $P$-sulfonated calix[4]arene not only increased the specific surface area of the modified electrode, but also improved the enrichment ability of tyrosine. The modifications were characterized by electrochemical impedance spectroscopy, cyclic voltammetry and molecular modeling calculation. Under optimal conditions, the sensor detected tyrosine with a limit of detection of $1.5 \times 10^{-9} \mathrm{~mol} \mathrm{~L}^{-1}$. The sensor was able to selective determination of tyrosine even

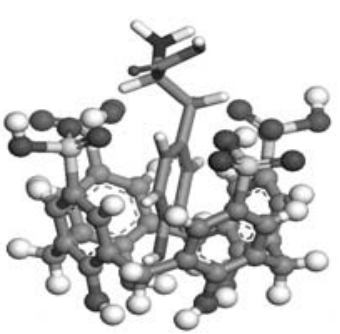
in the presence of common interference. The tyrosine guest molecule had a stronger $\pi \ldots \pi$ interaction with $p$-sulfonated calix[4] arene, which accelerated the electron transfer rate of tyrosine on the electrode surface, and increased the electrochemical activity. Therefore, the biosensor was highly selective. The sensor also showed good operational stability, sensitivity, repeatability and reproducibility.
\end{abstract}

\section{INTRODUCTION}

As the third major class of host molecules, calixarenes, ${ }^{1}$ which are synthesized by the condensation between $p$-alkylphenol and formaldehyde under basic condition, have attracted much attention due to their outstanding molecular recognition properties. $^{2,}{ }^{3}$ Calixarenes, as a macrocyclic platform, have a particular cavity conformation. ${ }^{4}$ It can adjust the cavity dimension and form inclusion compounds with various guest molecules. $P$-sulfonated calix $[n]$ arenes, ${ }^{5}$ as the water-soluble hosts, are of particular recognition interest towards native amino acids, ${ }^{6,7}$ quaternary ammonium ions, ${ }^{8,9}$ dyes, ${ }^{10,11}$ trimethylammonium cations, ${ }^{12-14}$ and a lot of small molecules. ${ }^{15}$ Therefore, the use of $p$-sulfonated calix[4]arene in pharmaceutical and biological aspects has aroused extensive interest. $^{7,16,17}$
Tyrosine $^{18}$ is an important amino acid in the human body and is an important material for the synthesis of catecholamines. A deficiency or imbalance of tyrosine leads to slow growth and mental retardation. Therefore, the accurate and sensitive determination of tyrosine in human tissues and body fluids is of great significance. The properties of amino acids have been studied by various methods such as spectrofluorometric, ${ }^{19}{ }^{1} \mathrm{H}$ NMR spectroscopy, ${ }^{20}$ microcalorimetry, ${ }^{21}$ reversephase high-performance liquid chromatography, ${ }^{22}$ voltammetric ${ }^{23}$ and other electrochemical methods. ${ }^{24}$ ${ }^{27}$ Tyrosine, as one of most basis amino acid, plays an important role in the growth, development, and metabolism of humans and animals, has been attracting much attention in medicine.

We used several techniques to study the interaction of tyrosine with $p$-sulfonated calix[4] arene (SC4A) (Figure 1). The coverage of

\footnotetext{
*Corresponding author: ptt801203@126.com
} 
the gold electrode with the different $p$-sulfonated calix[4] arene layers was characterized by scanning electron microscopy (SEM), Fourier transform infrared spectroscopy (FTIR), Ultraviolet spectroscopy (UV), cyclic voltammetry (CV) and electrochemical impedance spectroscopy (EIS). The effects of the tyrosine concentration, applied potential and $\mathrm{pH}$ value of phosphate buffer solution (PBS) were also discussed through Nyquist plot. Molecular modeling calculation confirmed that SC4A has high tyrosine sensitivity.

\section{EXPERIMENTAL}

\section{Reagents}

All chemicals were of analytical reagent grade, and double-distilled water was used throughout the procedures. The tyrosine (content $>98.0 \%$ ) used in the experiment was obtained from Tokyo Chemical industry (Tokyo, Japan). SC4A was prepared according to literature ${ }^{28}$ and identified by $\mathrm{IR},{ }^{1} \mathrm{H}$ NMR and element analysis. SC4A $(n=4,6,8)$ and tyrosine stock solutions $\left(1.0 \times 10^{-3} \mathrm{~mol} \mathrm{~L}^{-1}\right)$ were prepared in a $100 \mathrm{ml}$ volumetric flask. Working solutions were obtained by dilution of the stock solution. All the stock standard solutions were stable for several weeks in the refrigerator.

\section{Apparatus}

The nanostructures and morphology of sample were studied by JSM-7500F scanning electron microscope (SEM).

FTIR spectra obtained from Agilent 600 spectrometer equipped with a Middle Infrared (MIR) source, a DTGS detector and a $\mathrm{KBr}$ separating mirror. Spectra were measured at a resolution of $4 \mathrm{~cm}^{-1}$, and 32 scans per sample were recorded. Ultraviolet spectra measurements were obtained using an Agilent technologies cary 300.

Electrochemical measurements were performed on a LK2005A Electrochemical Workstation (Tianjin, China). A classical three-electrode system was used throughout the experiments. The working electrode was a modified gold electrode; the auxiliary electrode was a platinum wire and a saturated calomel electrode (SCE) was used as the reference. All potentials in this paper refer to this reference electrode.
Molecular modeling calculations were optimized at the B3LYP/6-31G (d) level of density functional theory with the Gaussian 03 program.

\section{RESULTS AND DISCUSSION}

\section{Scanning electron microscopy}

The morphologies and microstructures of SC4A, tyrosine, and SC4A-tyrosine complex were studied by scanning electron microscopy (Fig. 2). Fig 2a displayed the SEM of SC4A with the irregular quadrate shaped molecular islands. As shown in Fig. 2b, tyrosine grows in irregularly rectangular structure. It was obvious from the image that in the complex formation tyrosine was enclosed in SC4A and became mass due to the presence of tyrosine molecules in them (Fig. 2c).

\section{FTIR spectroscopy}

Figures 3a-c showed the FTIR spectrum of SC4A, tyrosine, and SC4A-tyrosine complex between 400 and $4000 \mathrm{~cm}^{-1}$. Figure 3a showed peaks at $1670 \mathrm{~cm}^{-1}$ to $1300 \mathrm{~cm}^{-1}$ which corresponded to aromatic ring stretching. The peak at $1200 \mathrm{~cm}^{-1}$ and $1050 \mathrm{~cm}^{-1}$ was assigned to $\mathrm{S}=\mathrm{O}$ stretching. The strong peaks at $3400 \mathrm{~cm}^{-1}$ region was assigned to $\mathrm{O}-\mathrm{H}$ stretching. Figure $3 \mathrm{~b}$ showed peaks at $1600 \mathrm{~cm}^{-1}$ to $1300 \mathrm{~cm}^{-1}$ which corresponded to aromatic ring stretching. The peaks at $3000 \mathrm{~cm}^{-1}$ to $2500 \mathrm{~cm}^{-1}$ were assigned to $\mathrm{COOH}$ stretching. The peak at $3200 \mathrm{~cm}^{-1}$ was assigned to $\mathrm{N}-\mathrm{H}$ stretching. The strong peak at $3400 \mathrm{~cm}^{-1}$ region was assigned to $\mathrm{O}-\mathrm{H}$ stretching. The identified chemical groups of SC4A were all shown in Figures 3c, and only the $\mathrm{N}-\mathrm{H}$ and $\mathrm{O}-\mathrm{H}$ absorption peaks of tyrosine appeared which indicated that the complexes were formed.

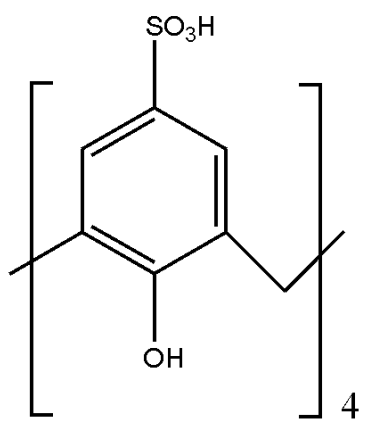

a

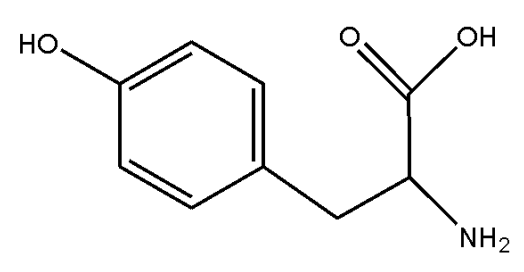

b

Fig. 1 - The structure of (a) $p$-sulfonated calix[4]arene and (b) the tyrosine. 

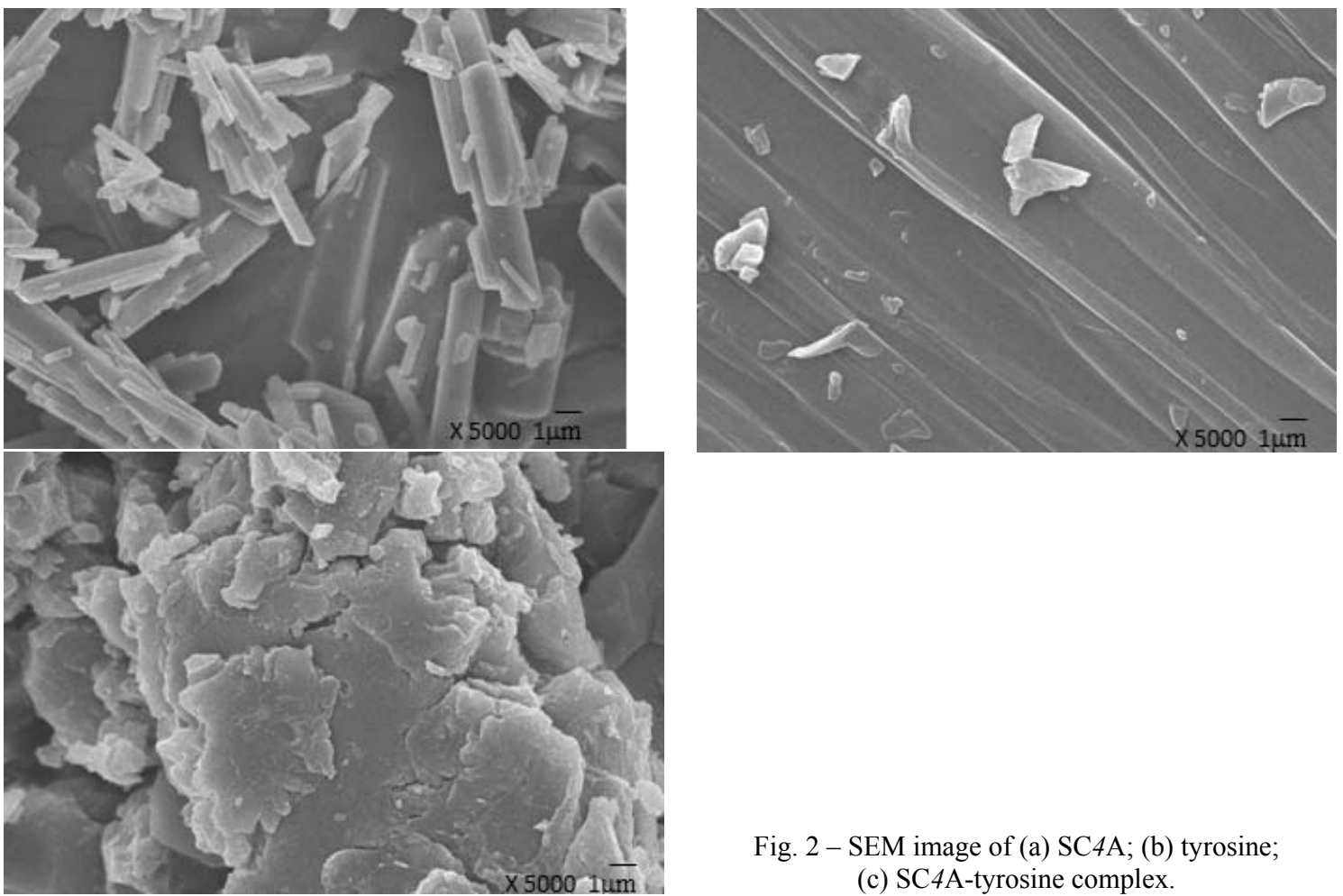

Fig. 2 - SEM image of (a) SC4A; (b) tyrosine;

(c) SC4A-tyrosine complex.

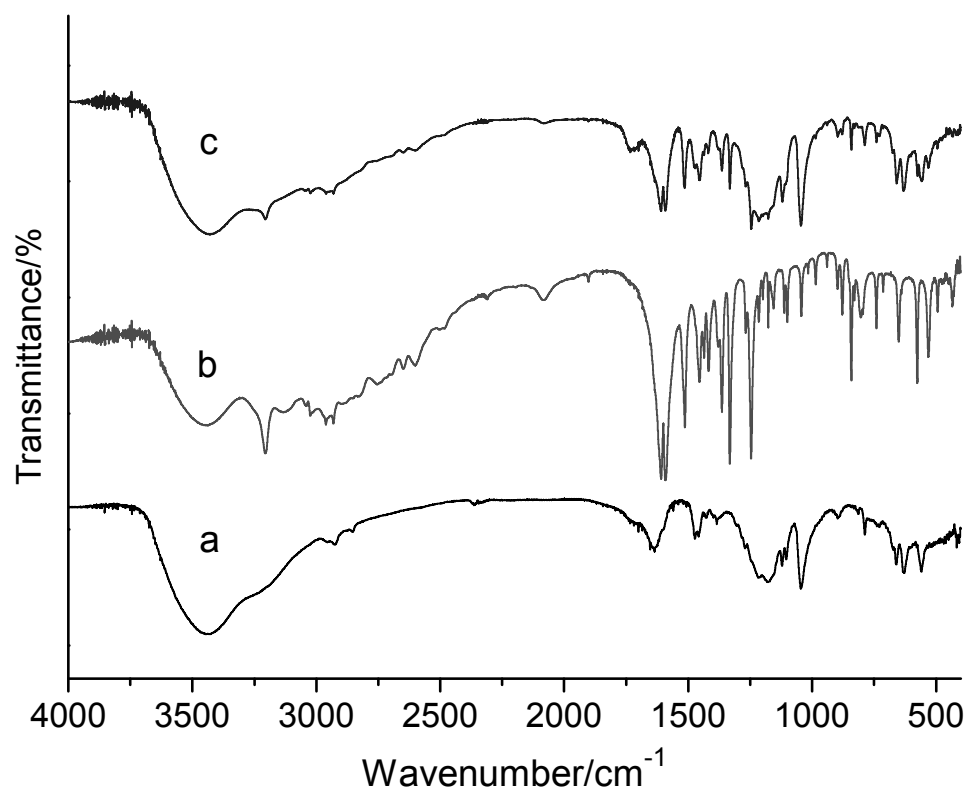

Fig. 3 - Infrared spectra of (a) SC4A; (b) tyrosine; (c) SC4A-tyrosine complex.

\section{Ultraviolet spectrum analysis}

Tyrosine has UV absorption, thus the UV spectrum analysis was used to study the inclusion behavior of tyrosine and SC4A. Figure 4 showed the absorption spectra of tyrosine changed with addition of different amounts of SC4A. As different amounts of SC4A were added, the absorption peak intensity significantly increased. The absorption wavelength generated an obvious blue shift from $280 \mathrm{~nm}$ to $265 \mathrm{~nm}$, and red shift from $330 \mathrm{~nm}$ to $340 \mathrm{~nm}$. Significant peak intensity increasing and the peak position shift indicated that the complexes were formed. 


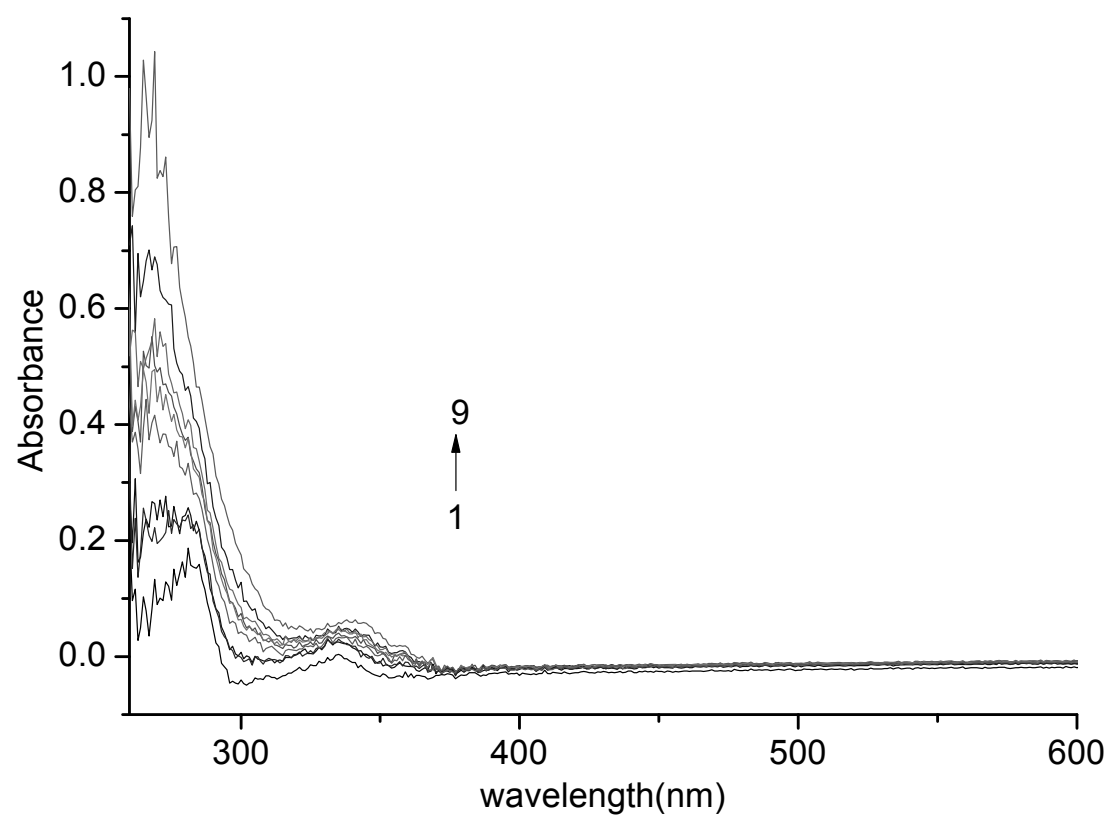

Fig. 4 - The UV adsorption spectra of tyrosine in different concentrations of SC4A in $\mathrm{pH}=7.2 \mathrm{PBS}$ at $298 \mathrm{~K}$; The concentrations of SC4A $\left(\times 10^{-5} \mathrm{~mol} \mathrm{~L}^{-1}\right)$ : (1) 0 ; (2) 0.1 ; (3) 0.3 ; (4) 0.5 ; (5) 0.6 ; (6) 0.8 ; (7) 1 ; (8) 1.5 ; (9) 2 . C (tyrosine) $=10^{-5} \mathrm{~mol} \mathrm{~L}^{-1}$.

\section{Cyclic voltammetry}

Cyclic voltammetry measurement was performed in a $5 \mathrm{~m} \mathrm{~mol} \mathrm{\textrm {L } ^ { - 1 }}$ solution of redox couple $\left(\mathrm{Fe}(\mathrm{CN})_{6}\right)^{4-/ 3-}$ prepared in PBS buffer. Scanning potential was conducted between -800 and $800 \mathrm{mV}$. Figure 5 showed the electrochemical behavior of tyrosine with the bare gold electrode and SC4A-modified electrode. Two peaks, which indicated the oxidation-reduction potential of the redox couple, were clearly observed on the cyclic voltammogram of tyrosine determined on the bare gold electrode. However, the oxidation peak value and reduction peak value were not the same and their peak shape was asymmetric, which indicated an irreversible redox reaction of tyrosine on the bare gold electrode. The peak current response value of tyrosine on the SC4A electrode, was higher than that obtained on the bare gold electrode, thus, tyrosine had a better electrochemical response on the modified electrode. The reason for this is that SC4A has good electrochemical activity, and as modified electrodes, SC4A has a large surface area, which led to a significant increase on the electrode surface area and electron transfer occurred more easily on the electrode surface.

\section{Electrochemical Impedance Spectroscopy}

Figure 6a showed the Nyquist plot of the bare gold electrode, gold electrode functionalized by
SC4A in PBS solution. The EIS of the bare gold electrode exhibited an almost straight line, which implied the diffusion-limiting step of the electrochemical process. The diameter of semicircle corresponded to $R_{1}=6.59 \mathrm{k} \Omega \mathrm{cm}^{2}$. As shown in Fig. 6b, a Randles circuit presented the impedance spectra. SC4A not only increased the specific surface area of the modified electrode, but also improved the enrichment ability of tyrosine.

\section{Optimization for the experimental conditions}

EIS was used to monitor the preparation process of modified electrodes, which could provide significant information and probe the impedance changes of the electrode surface during modification. ${ }^{29-31}$ The experimental impedance spectra were fitted by computer simulation using an equivalent electronic circuit based on the Randles-Ershler theoretical model. ${ }^{32,33}$ The impedance analysis was performed with a Voltalab 80 impedance analyser in the frequency range between $100 \mathrm{mHz}$ and $100 \mathrm{kHz}$.

Applied potential and solution $\mathrm{pH}$ are known to be important factors affecting the stability and performance of the modified electrode. SC4A modified gold electrode was analyzed by impedance spectroscopy at different applied potentials (Figure 7) and different $\mathrm{pH}$ (Figure 8). Different concentrations of tyrosine were injected in the PBS buffer solution to study SC4A-tyrosine interactions. 


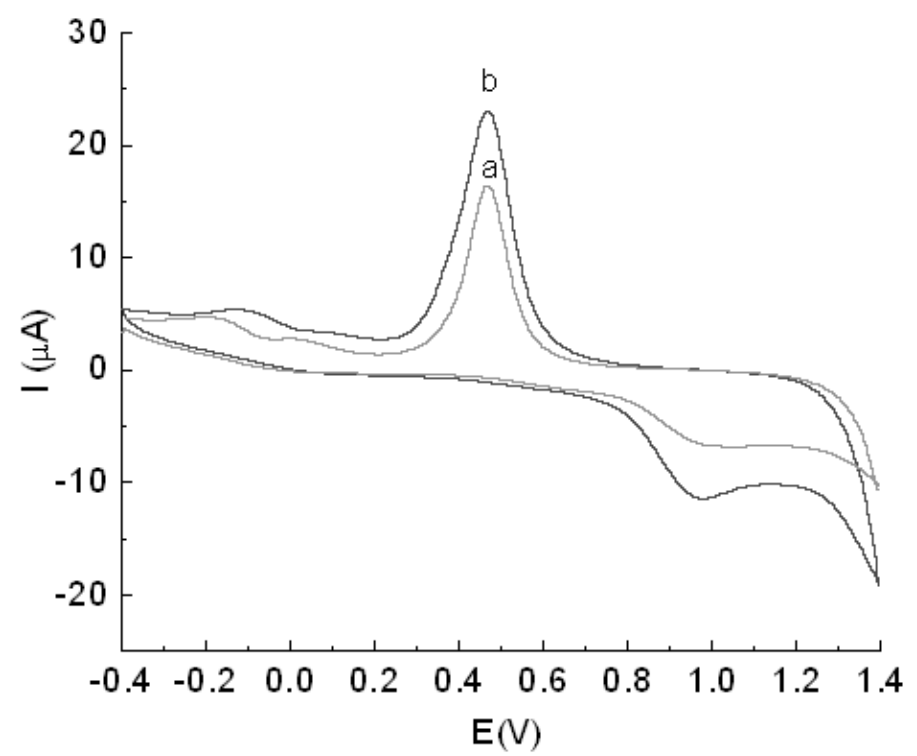

Fig. 5 - Cyclic voltammograms of L-tyrosine on the different modified electrodes (a) bare gold (b) SC4A/gold.

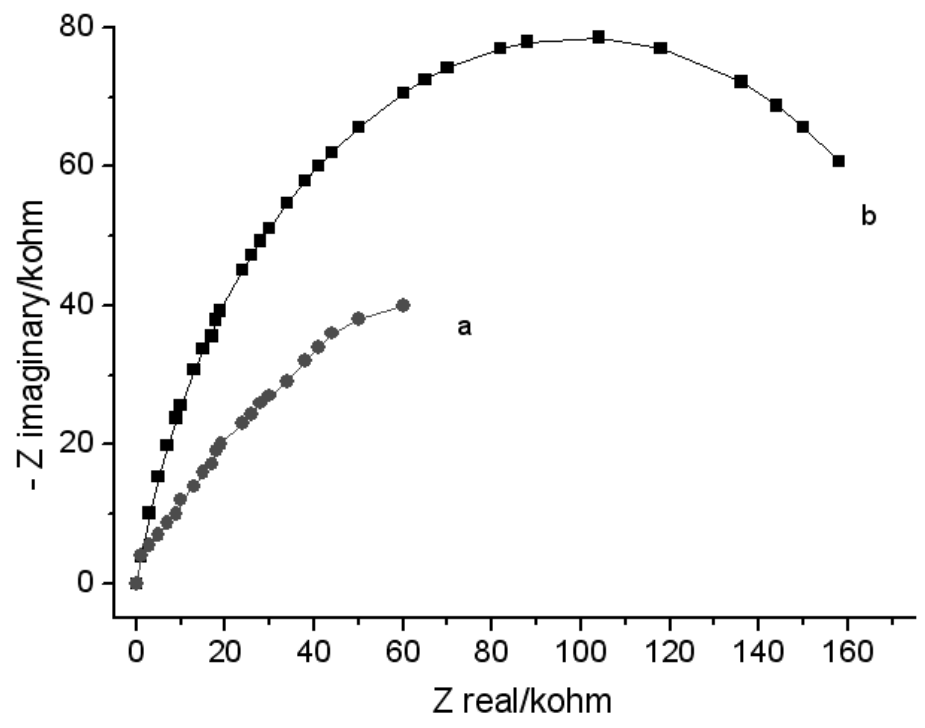

a

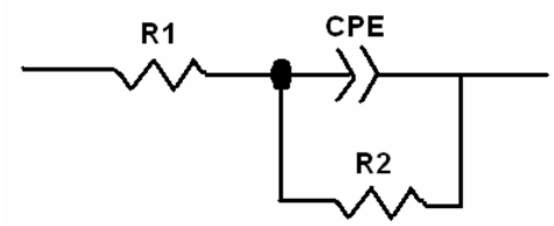

b

Fig. 6 - (a) Nyquist plot of the bare gold electrode, SC4A modified gold electrode in PBS solution. (b) Randles circuit.

Figure 7 showed the Nyquist plot of SC4A modified gold electrode at different applied potentials. Impedance analysis was carried out at a potential of $-400 \mathrm{mV}$ versus SCE because the best semicircle shape showed at $-400 \mathrm{mV}$. Figure 8 showed the optimum condition was at $\mathrm{pH} 7.3$ for tyrosine detection in $0.1 \mathrm{~mol} \mathrm{~L}^{-1} \mathrm{PBS}$. Therefore, $\mathrm{pH} 7.3$ was selected for all experiments.

\section{Tyrosine $-p$-sulfonated calix $[4]$ arene interaction}

Figure 9-1 showed the oxidation peak current of tyrosine decreased and the oxidation peak potential appeared a negaitive shift with addition of different
SC4A concentration. A plot of $\triangle \mathrm{I}$ versus $\mathrm{C}_{\mathrm{SC} 4 \mathrm{~A}}$ was linear within experiment error, which was showed in Figure 9-2. The linear response range of SC4A concentration was from $1 \times 10^{-8} \mathrm{~mol} \mathrm{~L}^{-1}$ to $1 \times 10^{-6} \mathrm{~mol} \mathrm{~L}^{-1}$, and the linear regression equation and correlation coefficient was as follows:

$$
\Delta \mathrm{I}(\mathrm{A})=5.1365 \mathrm{C}-6.7259 \times 10^{-7} \quad\left(\mathrm{r}^{2}=0.9996\right)
$$

Where $\Delta \mathrm{I}$ is the oxidation peak current difference of tyrosine and $C$ is the concentration of $\mathrm{SC} 4 \mathrm{~A}$. The detection limit was $1.5 \times 10^{-9} \mathrm{~mol} \mathrm{~L}^{-1}$. These values were determined by dividing the intercept by the slope of the corresponding lines. 


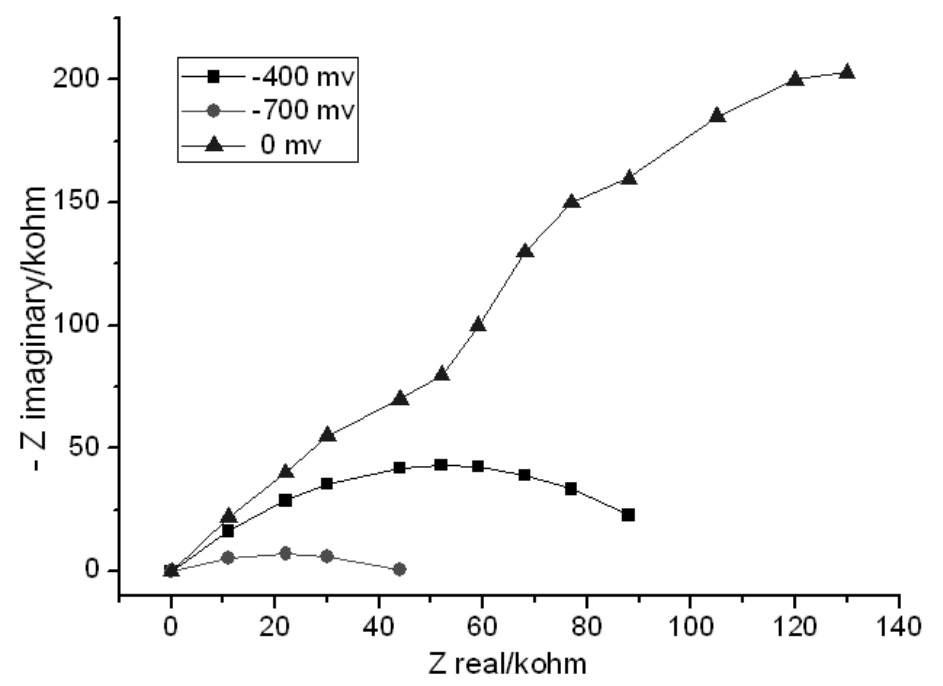

Fig. 7 - Nyquist plot of the gold electrode modified by SC4A at different applied potentials in PBS buffer.

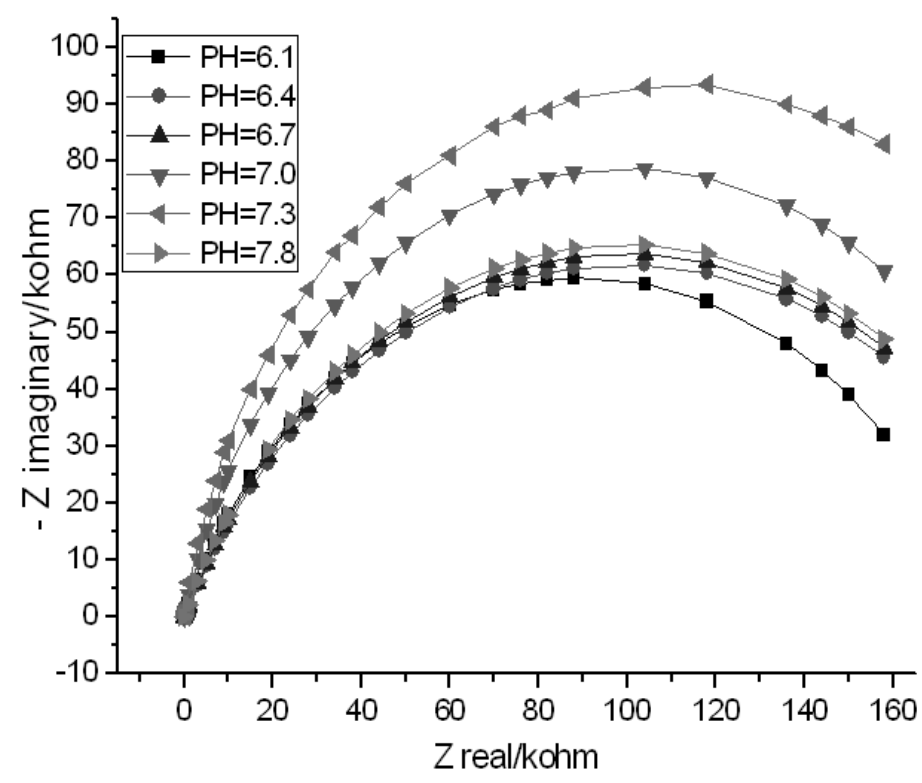

Fig. 8 - Nyquist plot of the gold electrode modified by SC4A in different $\mathrm{pH}$ varying from 6.1 to 7.8 in $0.1 \mathrm{~mol} \mathrm{~L}^{-1}$ PBS.

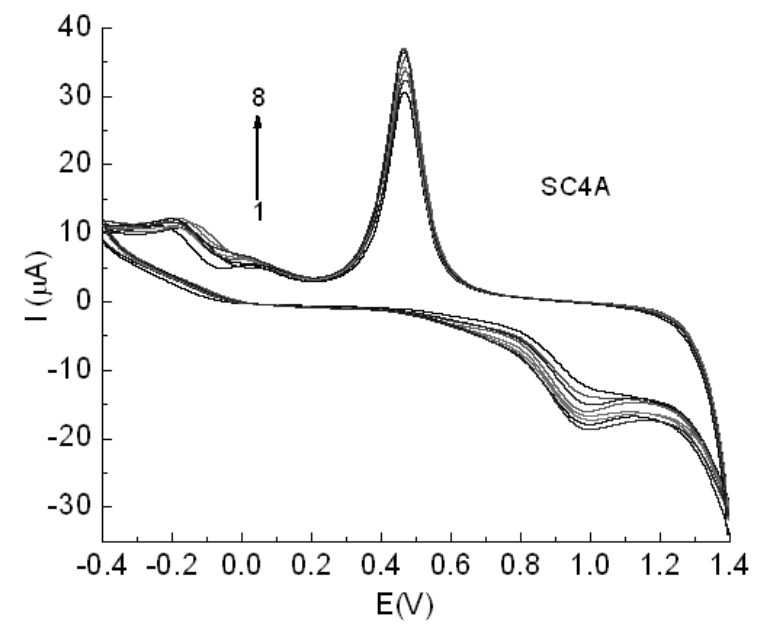

a

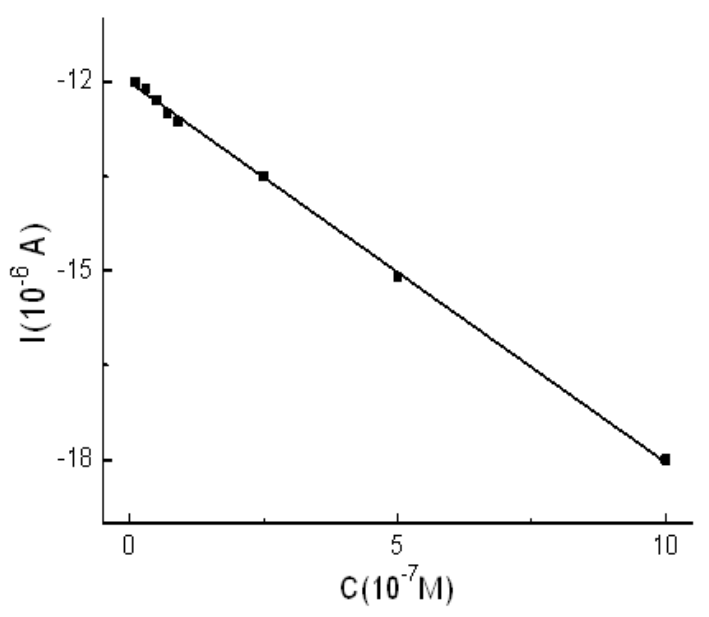

$\mathrm{b}$

Fig. 9 - Nyquist plot of different tyrosine concentration detected by SC4A in PBS buffer at pH 7.3. 
Assuming that $\mathrm{SCn} \mathrm{A}$ and colchicine forms SC4A- $n$ Tyr complex, the following expression can be written as:

$$
S C n A+n T y r \rightleftharpoons S C n A-n T y r
$$

The formation constant of the complex $(\beta)$ and binding number $(n)$ are given according to the literature: ${ }^{34}$

$$
\begin{gathered}
\beta=\frac{[S C n A-n T y r]}{[T y r]^{n}[S C n A]}: \\
{[S C n A]=[S C n A]_{o}-[S C n A-n T y r]} \\
{[T y r]=[T y r]_{o}-n[S C n A-n T y r]}
\end{gathered}
$$

According to Randles-Ševcik formula:

$$
\begin{gathered}
i_{p}=K[\text { Tyr }] \\
\Delta i=i_{p a}(\text { Tyr })_{o}-i_{p a}(T y r) \\
\Delta I=K\left([\text { Tyr }]_{o}-[\text { Tyr }]\right)=K \cdot n[S C n A-n T y r](7)
\end{gathered}
$$

In which, $[\mathrm{Tyr}]_{0}$ is the original concentration of the tyrosine; [Tyr], [SCnA] and [SCnA-nTyr] is the equilibrium concentration of the tyrosine, $\mathrm{SCn} \mathrm{A}$ and $\mathrm{SCnA}-\mathrm{Tyr} ; \mathrm{i}_{\mathrm{pa}}(\mathrm{Tyr})_{0}$ and $\mathrm{i}_{\mathrm{pa}}(\mathrm{Tyr})$ is the oxidation peak current of tyrosine before and after $\mathrm{SC} n \mathrm{~A}$ addition; $K$ is a fixed value, the product of all parameters in the Randles-Ševcik formula.
When $[\mathrm{SC} n \mathrm{~A}-\mathrm{nTyr}]=[\mathrm{SC} n \mathrm{~A}]_{0}, \triangle \mathrm{I}=\triangle \mathrm{I}_{\max }$,

$$
\begin{gathered}
\Delta I_{\text {max }}=K \cdot n[S C n A]_{o} \\
\frac{1}{\Delta I}=\frac{1}{\Delta I_{\text {max }}}+\frac{1}{\beta \Delta I_{\text {max }}[T y r]^{n}} \\
\log \frac{\Delta I}{\Delta I_{\text {max }}-\Delta I}=\log \beta+n \log [\text { Tyr }]
\end{gathered}
$$

In which, $\Delta \mathrm{I}$ is the oxidation peak current difference of tyrosine before and after $\mathrm{SCn} A$ addition; $\Delta \mathrm{I}_{\max }$ is the biggest oxidation peak current difference of tyrosine after SCnA addition; $\mathrm{n}$ is the binding number.

The excellent linear relationship was obtained when $\log \frac{\Delta I}{\Delta I_{\max }-\Delta I}$ was plotted against $\log [\operatorname{Try}]$ (Figure 4-1, 4-2). The liner equation was $\log \frac{\Delta I}{\Delta I_{\max }-\Delta I}=5.7+1.02 \log [$ Try $], \mathrm{r}^{2}=0$ .9996. $\mathrm{n}=1.02 \approx 1, \beta=5.59 \times 10^{7}$, which indicated the formation of a $1: 1$ complex.

In order to make a distinct comparison with

\begin{tabular}{|c|c|c|c|}
\hline Electrochemical sensors & $\begin{array}{l}\text { Linear range } \\
\left(10^{-6} \mathrm{~mol} \mathrm{~L}^{-1}\right)\end{array}$ & $\begin{array}{c}\text { Detection } \\
\text { Limit } \\
\left(10^{-6} \mathrm{~mol} \mathrm{~L}^{-1}\right)\end{array}$ & References \\
\hline MWCNT/4-amino benzene sulfonic acid/GCE & $0.1-50$ & 0.08 & {$[35]$} \\
\hline MWCNT, GCE & $0.9-350$ & 0.35 & [36] \\
\hline MWCNT, ionic liquid, copper (II)/GCE & $0.01-5$ & 0.008 & [37] \\
\hline $\mathrm{Cu}(\mathrm{II}), \mathrm{HMDE}^{\mathrm{a}}$ & $0.1-50$ & 0.05 & [38] \\
\hline Zeolite/carbon paste & $1.26-90$ & 0.32 & [39] \\
\hline Boron-doped diamond electrode & $20-1000$ & 1 & [40] \\
\hline MWCNT/GCE & $2-500$ & 0.4 & [41] \\
\hline Gold nanoparticles/GCE & $0.1-300$ & 0.04 & [42] \\
\hline Copper (II), MICP, MIP & $0.01-1$ & 0.004 & [43] \\
\hline Fe-hydroxyapatite/tyrosinase & $0.1-11$ & 0.245 & [44] \\
\hline$\beta-C D{ }^{b}$ modified gold electrode & $36-240$ & 12 & {$[45]$} \\
\hline EuHCF ${ }^{c}$ modified graphite electrode & $10-600$ & 8 & {$[46]$} \\
\hline GCE/SWCNT & $5-20$ & 0.09 & [47] \\
\hline $\mathrm{Au}$ NPs/poly (trisamine)/GCE & $3.9-61.8$ & 0.9 & [48] \\
\hline fMWCNT-Au-HP $\beta-C D / G C E$ & $220-870$ & 300 & [49] \\
\hline SC4A modified gold electrode & - & 0.0015 & This work \\
\hline
\end{tabular}
previous literature reported methods, the characteristics of different electrochemical sensors for tyrosine were shown in Table $1{ }^{35-49}$ It indicated SC4A modified gold electrode was appropriate platforms for the electrochemical determination of tyrosine and had higher sensitivity to tyrosine (Table 1).

Table 1

Comparison of different electrochemical sensors used in the determination of tyrosine

$\mathrm{HMDE}^{\mathrm{a}}$ : Hanging mercury drop electrode $\beta-\mathrm{CD}^{\mathrm{b}}$ : Cyclodextrin

EuHCF $^{\mathrm{c}}$ : Europium hexacyanoferrate film 


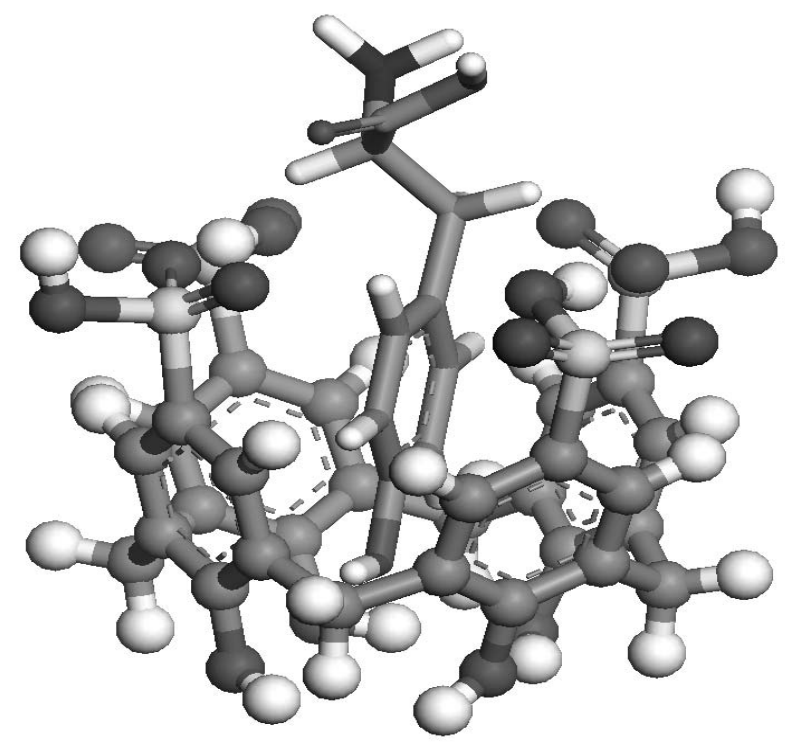

Fig. 10 - Lowest energy structure of tyrosine and SC4A complex using ball and stick model determined by molecular dynamics simulation with direct minimization.

Table 2

Effect of potential interfering species on the determination of tyrosine at level of $5 \times 10^{-5} \mathrm{~mol} \mathrm{~L}^{-1}$

\begin{tabular}{ccccc}
\hline Interference & $\begin{array}{c}\text { Interference } \\
\text { concentration } \\
\left(10^{-5} \mathrm{~mol} \mathrm{~L}^{-1}\right)\end{array}$ & $\begin{array}{c}\text { Found } \\
\left(10^{-5} \mathrm{~mol} \mathrm{~L}^{-1}\right)\end{array}$ & $\begin{array}{c}\text { Relative error } \\
(\%)\end{array}$ & $\begin{array}{c}\text { Recovery } \\
(\%)\end{array}$ \\
\hline $\mathrm{Mg}^{2+}$ & 0.1 & 5.20 & +4.00 & 104 \\
$\mathrm{Ca}^{2+}$ & 0.1 & 5.10 & +2.00 & 102 \\
$\mathrm{Na}^{+}$ & 0.1 & 5.05 & +1.00 & 101 \\
$\mathrm{~K}^{+}$ & 0.1 & 4.95 & -1.00 & 99 \\
L-lysine & 0.01 & 4.80 & -4.00 & 96 \\
L-asparagines & 0.01 & 5.12 & +2.40 & 102.4 \\
Ascorbic acid & 0.01 & 5.22 & -3.40 & 104.4 \\
Glycine & 0.01 & 4.85 & +3.00 & 97 \\
Phenylalanine & 0.01 & 5.15 & +3.60 & 103 \\
L-cysteine & 0.01 & 5.18 & -2.80 & 103.6 \\
Urea & 0.001 & 4.86 & -2.40 & 97.2 \\
Sucrose & 0.001 & 4.88 & +5.00 & 97.6 \\
Lactase & 0.001 & 5.25 & +4.80 & 105 \\
Galactose & 0.001 & 5.24 & +0.60 & 104.8 \\
Boric acid & 0.001 & 5.03 & -5.00 & 100.6 \\
Oxalic acid & 0.001 & 4.75 & 0 & 95 \\
Glutathione & 0.001 & 5.00 & & 100 \\
\hline
\end{tabular}

Table 3

Determination of tyrosine in real samples using the proposed sensor and HPLC as reference method

\begin{tabular}{llcccc}
\hline Sample & Method & $\begin{array}{c}\text { Detected } \\
\left(10^{-6} \mathrm{~mol} \mathrm{~L}^{-1}\right)\end{array}$ & $\begin{array}{c}\text { Added } \\
\left(10^{-6} \mathrm{~mol} \mathrm{~L}^{-1}\right)\end{array}$ & $\begin{array}{c}\text { Found } \\
\left(10^{-6} \mathrm{~mol} \mathrm{~L}^{-1}\right)\end{array}$ & $\begin{array}{c}\text { Recovery } \\
(\%)\end{array}$ \\
\hline Egg & Sensor & 3.56 & 2.00 & 5.57 & 100.5 \\
Egg & HPLC & 4.21 & 2.00 & 6.24 & 101.5 \\
Cheese & Sensor & 3.88 & 2.00 & 5.89 & 100.5 \\
Cheese & HPLC & 6.22 & 2.00 & 8.19 & 98.5 \\
Yogurt & Sensor & 5.12 & 2.00 & 7.12 & 100 \\
Yogurt & HPLC & 4.65 & 2.00 & 6.64 & 99.5 \\
\hline
\end{tabular}

Tyrosine produced more reactive sites on the $p$-sulfonated calix[4]arene-modified electrode, which increased electron transfer. This led to a significant increase in peak current, and improved the sensitivity of tyrosine determination on the SC4A modified electrode. 
It may be attributed to the interaction between the $-\mathrm{NH}_{2}{ }^{+}$of tyrosine and the $-\mathrm{SO}_{3}{ }^{-}$of calixarene, and the cavity size of SC4A may be appropriate to tyrosine. This finding was consistent with the trend observed in molecular modeling calculation results, ${ }^{50}$ as shown in Figure 10.

Therefore the structural matching effect and the electrostatic interaction were the dominant stabilizing factors for the host-guest complex of the tyrosine and SC4A. The presence of this effect increased tyrosine sensitivity by increasing the SC4A- tyrosine interaction due to increased polarisability interactions.

\section{Interference study}

To evaluate the selectivity of the constructed tyrosine sensor, the influence of several interfering agents such as urea, sucrose, galactose, boric acid, oxalic acid, L-lysine, L-asparagines, glycine, phenylalanine, glutathione, L-cysteine, ascorbic acid, $\mathrm{Mg}^{2+}, \mathrm{Ca}^{2+}, \mathrm{Na}^{+}, \mathrm{K}^{+}$and lactase on the determination of $5 \times 10^{-5} \mathrm{~mol} \mathrm{~L}^{-1}$ tyrosine under the optimal experimental conditions was investigated. The results are listed in Table 2. The tolerance limit was computed as the maximum concentration of the interfering agent which caused an approximately $\pm 5 \%$ relative error in the determination of tyrosine concentration. The data showed that the current SC4A modified electrode is highly selective for the detection of tyrosine.

\section{Reproducibility and stability of SC4A modified gold electrode}

The reproducibility of SC4A gold modified electrode was respectively estimated using eight modified electrodes which were prepared under the same condition and used to detect the current response of $1 \times 10^{-6} \mathrm{~mol} \mathrm{~L}^{-1}$ tyrosine. The results showed that these electrodes had satisfying reproducibility with relative standard deviations (RSD) of $1.24 \%$ for SC4A for 50 successive measurements. The storage stability of each electrode was studied by storing them at $4{ }^{\circ} \mathrm{C}$ in a refrigerator when not in use and was intermittently measured. ${ }^{51}$ Five days later, the response of the SC4A gold modified electrode still retained 97.5\%. After 30 days, the response current of the modified electrode retained at around $90 \%$.

\section{Application \\ of the modified sensor to real samples}

Generally, after developing a new analytical method and validating its performance for the analysis of synthetic samples, its performance is compared with a reference method to verify its capability for the analysis of real samples. ${ }^{52}$ Then, the newly developed analytical method could be suggested as a reliable method for routine analyses. Regarding this important step, we have also applied HPLC analysis of the cheese, egg and yogurt as real samples towards tyrosine determination and its results are presented in Table 3. As it can be seen, good recoveries confirmed that there was an acceptable agreement between its results and those obtained by the sensor fabricated in this study.

\section{CONCLUSIONS}

In this report we studied the potential complex formation between $\mathrm{SC} 4 \mathrm{~A}$ and tyrosine using electrochemical impedance spectroscopy. Tyrosine is one of the amino acids which is necessary for maintenance of nutritional balance and its level in the body is correlated to the healthy state of the person. Therefore, in this work, a novel and ultrasensitive electrochemical sensor based on SC4A modified gold electrode for determination of tyrosine in some high tyrosine foods including.

The sensor could be easily modified which showed high sensitivity, selectivity, fast response time and good reproducibility and repeatability towards tyrosine determination in both synthetic and real samples. Molecular modeling calculation reconfirmed EIS results and indicated that the electrostatic interaction and the structural matching effect were the dominant stabilizing factors for the host-guest complexes of the tyrosine and SC4A. The sensor modified in this study could be applied for a wide range of applications in routine analyses of tyrosine.

Acknowledgements. This work was supported by Doctoral Scientific Research Foundation of shanxi Province (No. 050502070397) and Coal seam gas Joint Foundation of Shanxi (No. 2016012013). Helpful suggestions by anonymous referees are also gratefully acknowledged. 


\section{REFERENCES}

1. B. Korchowiec, M. Gorczyca, A. Salem, J. Regnouf and E. Rogalska, Colloid. Surf. B., 2013, 103, 217-223.

2. P. Rajannu, P. Elumalai, F. Hussain and M. Sathiyendiran, J. Orgmet. Chem., 2013, 725, 1-4.

3. X. P. Ding, D. B. Tang, T. Li, S. F. Wang and Y. Y. Zhou, Spectrochimi. Acta. A., 2011, 81, 44-47.

4. M. Chen, T. Shang, S. J. Liu and G. W. Diao, J. Chem. Ther., 2011, 43, 88-93.

5. Y. Y. Zhou, Q. Lu, C. Liu, S. K. She and L. Wang. Anal. Chim. Acta., 2005, 552, 152-159.

6. E. Silva, P. Shahgaldian and A. Coleman, Int. J. Pharmaceut., 2004, 273, 57-62.

7. M. Michele, H. Andreas and B. Carlito, J. Am. Soc. Mass. Spectr., 2002, 13, 964-974.

8. A. Arena, N. Donato, G. Saitta, A. Bonavita, G. Rizzo and G. Neri, Sensors. Actuat. B., 2010, 145, 488-494.

9. R. Arnecke, V. Böhmer, R. Cacciapaglia, A. Cort and L. Mandolini, Tetrahedron, 1997, 53, 4901-4908.

10. A. Yilmaz, E. Yilmaz, M. Yilmaz and R. Bartsch, Dyes Pigments, 2007, 74, 54-59.

11. E. Akceylan, M. Bahadir and M. Y1lmaz, J. Hazard. Mater., 2009, 162, 960-966.

12. B. Nimse, J. Kim, K. Song, J. Kim, J. Lee, V. Nguyen, V. Ta and T. Kim, Tetrahedron Lett., 2011, 52, 37513755.

13. G. Arena, S. Gentile, F. Gulino, D. Sciotto and C. Sgarlata, Tetrahedron Lett., 2004, 45, 7091-7094.

14. T. Komura, T. Yamaguchi, K. Kura and J. Tanabe, J. Elec. Chem., 2002, 523, 126-135.

15. G. Arena, A. Contino, F. G. Gulino, A. Magri, D. Sciotto and R. Ungaro, Tetrahedron Lett., 2000, 41, 9327-9330.

16. J. S. Millership, L. G. Hare, M. Farry, P. S. Collier, J. C. McElnay, M. D. Shields and D. J. Carson. J. Pharmaceut. Biomed., 2001, 25, 871-879.

17. J. Gualbert, P. Shahgaldian and A. W. Coleman. Int. J. Pharma., 2003, 257, 69-73.

18. S. Yabuki, F. Mizutani and Y. Hirata, Sensors Actuat B., 2001, 76, 142-146.

19. W. Y. Li, H. Li, G. M. Zhang, J. B. Chao, L. X. Ling, S. M. Shuang and C. Dong, J. Photochem. Photobi. A: Chem., 2008, 197, 389-393.

20. F. Angela, D. Namor, K. Baron, S. Chahine and O. Jafou, J. Phys. Chem. A., 2004, 108, 1082-1089.

21. Y. Liu, D. S. Guo, H. Y. Zhang, Y. H. Ma and E. C. Yang, J. Phys. Chem. B., 2006, 110, 3428-3434.

22. H. M. Chawla, N. Pant, S. Kumar, S. Mrig, B. Srivastava, N. Kumar and D. S. Black, J. Photochem. Photobi. B: Biology, 2011, 105, 25-33.

23. F. Wang, Y. J. Wu, K. Lu and B. X. Ye, Electrochimica Acta, 2013, 87, 756-762.

24. P. Leyton, I. Córdova, P. A. Lizama-Vergara, J. S. GómezJeria, A. E. Aliaga, M. M. Campos-Vallette, E. Clavijo, J. V. García-Ramos and S. Sanchez-Cortes, Vib. Spectrosc., 2008, 46, 77-81.
25. M. Chen, W. Zhang, R. M. Jiang and G. W. Diao, Anal. Chim. Acta., 2011, 687, 177-183.

26. S. Z. Kang, H. Chen, X. Q. Li and J. Ma, J. Diam. Relat. Mater., 2010, 19, 1221-1224.

27. X. Ba, L. Q. Luo, Y. P. Ding and X. Liu, Sensors. Actuat. B: Chem., 2012, 3, 1-6.

28. D. S. Guo, K.Wang, Y. X. Wang and Y. Liu, J. Am. Chem. Soc., 2012, 134, 10244-10250.

29. A. B. Kharitonov, L. Alfonta, E. Katz and I. Willner, J. Electroanal. Chem., 2000, 487, 133-141.

30. J. J. Feng, J. J. Xu and H. Y. Chen, Biosens. Bioelectron., 2007, 22, 1618-1624.

31. D. C. Jolly and D. L. Murray, J. Electroanal. Chem., 1984, 160, 103-116.

32. J. E. B. Randles, Discuss. Faraday Soc., 1947, 1, 11-19.

33. B. V. Ershler, Discuss. Faraday Soc., 1947, 1, 269-277.

34. T. T. Pang, X. Y. Zhang and Y. B. Xue, Anal. Lett., 2017, 50, 1743-1753.

35. K. Huang, D. Luo, W. Xie and Y. Yu, Colloids Surf. B., 2008, 61, 176-181.

36. J. Xu, Y. Wang, Y. Xian and L. Jin, Talanta, 2003, 60, $1123-1130$.

37. L. Liu, F. Zhao, F. Xiao and B. Zeng, Electroanalysis, 2008, 20, 2148-2152.

38. H. Liang, T. Ling, J. F. Rick and T. Chou, Anal. Chim. Acta., 2005, 542, 83-89.

39. A. Babaei, S. Mirzakhani and B. Khalilzadeh, J. Braz. Chem. Soc., 2009, 20, 1862-1869.

40. G. Zhao, Y. Qi and Y. Tian, Electroanal., 2006, 18, 830834.

41. Q. Xu and S. Wang. Microchim. Acta., 2005, 151, 47-52.

42. Z. Chen, K. Okamura, M. Hanaki and T. Nagaoka, Anal. Sci., 2002, 18,427-432.

43. V. Saumya, K. P. Prathish and T. P. Rao, Talanta, 2011, $85,1056-1062$.

44. P. Kanchana, N. Lavanya and C. Sekar, Mater. Sci. Eng. C., 2014, 35, 85-91.

45. C. Quintana, S. Suarez and L. Hernandez, Sens. Actuators B Chem., 2010, 149, 129-135.

46. Y. Liu, Z. Yang, Y. Zhong and J. Yu, Appl. Surf. Sci., 2010, 256, 3148-3154.

47. X. Yu, Z. Mai, Y. Xiao and X. Zou, Electroanalysi,. 2008, 20, 1246-1251.

48. M. Taei and G. Ramazani, Colloids Surf. B., 2014, 123, 23-32.

49. U. Yogeswaran, S. Thiagarajan and S. M. Chen, Carbon, 2007, 45, 2783-2796.

50. G. P. Jin and X. Q. Lin, Electrochem. Commun., 2004, 6, 454-460.

51. C. F. Ding, M. L. Zhang, F. Zhao and S. S. Zhang, Anal. Biochem., 2008, 378, 32-37.

52. K. Varmira, G. Mohammadi, M. Mahmoudi, R. Khodarahmi, K. Rashidi, M. Hedayati, H. C. Goicoechea and A. R. Jalalvand, Talanta, 2018, 183, 1-10 